\title{
La reducción del tráfico de automóviles: una política urgente de promoción de la salud ${ }^{1}$
}

\author{
José A. Tapia Granados²
}

RESUMEN En las últimas décadas, las lesiones de tráfico se han convertido en una de las primeras causas de muerte y discapacidad en todo el mundo. En las zonas urbanas la congestión, el ruido y las emisiones de los motores de los vehículos causan molestias subjetivas y efectos patológicos detectables. Más de mil millones de personas están expuestas a niveles de contaminación atmosférica nocivos.

Por su motor de combustión que genera dióxido de carbono $\left(\mathrm{CO}_{2}\right)$ el automóvil es una de las fuentes principales de gases inductores del efecto invernadero. Este efecto ha generado ya un incremento de la temperatura media atmosférica y se estima que producirá en los próximos decenios alteraciones climáticas significativas de consecuencias inciertas, pero muy probablemente nocivas y posiblemente catastróficas. Independientemente del efecto invernadero, el crecimiento constante del parque automovilístico, del tráfico y de la infraestructura viaria urbana y rural es hoy una de las causas principales de la degradación del ambiente. El desarrollo urbano, casi siempre "planificado" en función del tráfico y no de las personas, hace que empeore significativamente la calidad de la vida, a la vez que fractura el tejido social.

Frente al automóvil privado, el transporte público o en bicicleta y el desplazamiento a pie contribuyen a reducir la contaminación, la congestión y el volumen de tráfico, así como la morbilidad y mortalidad por lesiones y por enfermedades relacionadas con la contaminación. El transporte no automovilístico promueve también la actividad física —con un efecto de mejora general de la salud-y contribuye a aminorar el efecto invernadero. La reducción del volumen de tráfico y el impulso de métodos alternativos de transporte son así una política integral de promoción de la salud que ha de incorporarse en el movimiento de ciudades saludables, así como en las políticas de transporte y en la política económica en general.

La producción mundial anual de automóviles pasó de 11 millones en 1950 a 53 millones en $1995(1,2)$. Según estimaciones recientes (1995), en el mundo circulan más de 600 millones de vehículos automotores, de los cuales algo más de tres cuartas partes son automóviles y el resto camiones y auto-

\footnotetext{
1 Próximamente se publicará en esta revista una versión en inglés de este artículo.

2 Anteriormente, Organización Panamericana de la Salud, Oficina de Publicaciones y Servicios Editoriales, Washington, DC, EUA. Dirección actual para la correspondencia: 575 Third Street, \#3B, Brooklyn, NY 11215 EUA. Correo electrónico: tapiaj01@newschool.edu.
}

buses (2). De los 420 millones de automóviles en circulación a comienzos de los años noventa, unos 330 millones $(80 \%)$ se hallaban en los países industrializados de América del Norte, Europa Occidental y Oceanía, donde vive $18 \%$ de la población mundial. Los otros 90 millones (20\%) circulaban en el resto del mundo, donde vive $82 \%$ de la población (3). Entre países, las diferencias del índice de motorización (vehículos per cápita) son enormes y las del uso promedio de automóviles son aun mayores (cuadro 1).

En resumen, los efectos nocivos del tráfico pueden reducirse a lo siguiente: a) mortalidad, morbilidad y discapacidad generadas por lesiones; b) aumento de la mortalidad general y de la incidencia de diversas enfermedades, debido a la contaminación ambiental; c) desarrollo de sedentarismo y obesidad - con los consiguientes efectos patológicos- por falta de ejercicio físico; d) transformación de las ciudades en espacios donde el automóvil es hegemónico y desplaza a los demás usuarios de la vía pública, lo que crea un espacio urbano deshumanizado, que favorece la marginación y la desintegración social; e) desarrollo de una infraestructura via- 
CUADRO 1. Población, parque automovilístico, índice de motorización y utilización de automóviles en 12 países

\begin{tabular}{|c|c|c|c|c|c|c|}
\hline \multirow[b]{2}{*}{ País } & \multirow{2}{*}{$\begin{array}{l}\text { Población } \\
\text { en } 1995 \\
\text { (millones) }\end{array}$} & \multirow{2}{*}{$\begin{array}{c}\text { Automóviles } \\
\text { en } 1995 \\
\text { (millones) }\end{array}$} & \multicolumn{3}{|c|}{ Vehículos ${ }^{a}$ por 1000 habitantes } & \multirow{2}{*}{$\begin{array}{c}\text { km-automóvil } \\
\text { por año- } \\
\text { persona, hacia } \\
1988\end{array}$} \\
\hline & & & 1985 & 1991 & $\begin{array}{c}\text { Incremento } \\
(\%)\end{array}$ & \\
\hline Estados Unidos & 263,1 & 195,47 & 711 & $755^{\mathrm{b}}$ & $6^{c}$ & 8870 \\
\hline Alemania & 81,3 & 39,92 & 451 & 521 & 16 & 6150 \\
\hline Japón & 125,9 & 44,94 & 374 & 475 & 27 & 2510 \\
\hline Italia & 57,9 & 29,60 & 434 & 538 & 24 & 4030 \\
\hline Reino Unido & 58,1 & 23,83 & 348 & 415 & 19 & 4730 \\
\hline Argentina & 34,3 & 2,20 & 175 & 179 & 2 & 1000 \\
\hline Polonia & 38,7 & 3,51 & 122 & 193 & 58 & 710 \\
\hline Corea del Sur & 45,2 & 6,50 & 27 & 97 & 259 & 210 \\
\hline Guatemala & 10,6 & 0,04 & 24 & 20 & -16 & - \\
\hline Camerún & 13,3 & 0,01 & 12 & 8 & -33 & 120 \\
\hline Haití & 7,2 & 0,02 & 6 & - & - & - \\
\hline China & 1238,3 & 0,96 & - & $5^{d}$ & - & - \\
\hline
\end{tabular}

ria urbana y rural que detrae enormes recursos públicos, provoca un gran deterioro ambiental y perjudica la rentabilidad económica de otros medios de transporte mucho más eficientes y saludables; y f) emisión de dióxido de carbono $\left(\mathrm{CO}_{2}\right)$, con la consiguiente contribución al efecto invernadero.

Ya que los efectos nocivos del tráfico dependen directamente de su volumen, su reducción mediante el transporte colectivo y el fomento de otros medios de transporte no motorizados es una política integral y urgente de promoción de la salud. Probablemente esta idea provocará tanta oposición y escepticismo como lo hicieron en su momento - y aún lo hacen en muchos países- las políticas de prevención del tabaquismo. No obstante, la reducción del volumen de tráfico no solo es conveniente sino cada vez más necesaria e incluso urgente. En este artículo se presentan diversos datos para fundamentar esa idea.

\section{Causa y accidente: precisiones conceptuales}

En salud pública el concepto de causalidad ha suscitado mucha polémica (6), pero en la práctica los epidemiólogos suelen utilizar los criterios de Hill
(7) y consideran causas a los factores materiales o circunstanciales que aumentan la probabilidad de que un fenómeno ocurra. Así, el tabaco, el asbesto y el radón son causas de cáncer de pulmón porque la exposición a esos factores aumenta la probabilidad de que se produzca la neoplasia. Esta concepción probabilística de causa (8), que implica a menudo la multicausalidad, justifica hablar del tráfico como causa de mortalidad o morbilidad porque la circulación de automóviles genera el riesgo de lesiones en colisiones, atropellos y otros sucesos. Hay además una relación dosis-efecto, ya que el aumento del tráfico incrementa el número de eventos no intencionados $\mathrm{y}$, consiguientemente, las tasas de mortalidad o lesiones (véase más adelante).

La energía cinética del vehículo en marcha genera la posibilidad de traumatismos. El riesgo de colisión y, si esta se produce, la probabilidad de lesión o muerte, tienen relación con factores tan diversos como la hora del día, el día de la semana, el precio del combustible, las limitaciones legales de velocidad, la velocidad de tránsito, la densidad de circulación de vehículos y peatones, las características físicas de los vehículos - tipo, masa, altura, índice de estabilidad, presencia o ausencia de dispositivos de seguridad, de superficies angulosas, internas y externas, etc. - y las características personales - edad, género, clase social, estado psicofísico y otras- de los implicados (9-21). Estos factores intervienen en cadenas de causación en las que el suceso final no es ni más ni menos "accidental" que el caso concreto de hepatitis o cáncer, en cuya producción también interviene en cierta medida el azar (22). Por ello, diversos autores $(10,23-26)$ han propuesto evitar sistemáticamente el término "accidente", cuyas connotaciones de imprevisibilidad e incontrolabilidad son contraproducentes desde el punto de vista de la prevención. Desgraciadamente, el término sigue apareciendo una y otra vez, incluso en contextos epidemiológicos $(20,27)$. En la décima revisión de la Clasificación Internacional de Enfermedades (28), el capítulo XX dedicado a causas externas de morbilidad y de mortalidad sigue denominando "accidentes" a las lesiones producidas por vehículos de motor. La persistencia con que se siguen considerando accidentales los sucesos, muertes o lesiones no intencionales hace recordar la afirmación de Jeremías Bentham, quien decía que nunca es tan difícil refutar el error como cuando tiene sus raíces en el lenguaje. Sin embargo, contemporizar con una mala 
denominación difícilmente podrá ser punto de partida de una buena política de salud.

\section{Mortalidad por lesiones de tráfico}

Las estadísticas de morbilidad y mortalidad por lesiones de tráfico (LT) son problemáticas, por las diferencias en la codificación de las defunciones y por las deficiencias de notificación y registro (10). En muchos países puede haber una subestimación importante de la mortalidad por LT (29-31). A nivel mundial las estimaciones de mortalidad anual por esas lesiones arrojan cifras cada vez mayores. El cuarto de millón de defunciones que se calculó para 1980 (25) ascendió a 856000 para 1990 (32) y a 885000 para 1993 (33).

En los países industrializados, las LT son una de las tres primeras causas de muerte junto con las enfermedades cardiovasculares y el cáncer. En el resto del mundo son la tercera causa de muerte entre los varones de edad económicamente activa (34). En Kuwait y otros países productores de petróleo, las LT son la principal causa de muerte a todas las edades (35).

Mientras que el cáncer y las enfermedades cardiovasculares matan principalmente a edades avanzadas, las LT causan un gran número de defunciones entre adolescentes y adultos jóvenes. En los Estados Unidos de América las lesiones son la primera causa de pérdida de años de vida productiva $y$, dentro de las lesiones en general, las de tráfico ocupan el lugar principal (36).

En los países con bajo índice de motorización, la máxima mortalidad por LT se da a edades avanzadas. Dado que en esos países la mayor parte de las víctimas de LT son peatones (35), cabe suponer que son ancianos los que resultan atropellados más a menudo. En países altamente motorizados, la curva de mortalidad por edades es bimodal, con un máximo alrededor de los 20 años y otro a edades avanzadas (figura 1).

En todos los países la mortalidad por LT en mujeres es menor que en los varones a todas las edades, aunque las diferencias tienden a disminuir al aumentar el índice de motorización y en los Estados Unidos se están reduciendo drásticamente (37). A comienzos de los años noventa en los Estados Unidos la tasa correspondiente en varones fue algo más del doble que en mujeres, mientras que en Alemania y Brasil fue aproximadamente el triple y en México, el cuádruplo $(30,38)$. El predominio de la mortalidad por LT en varones, incluso a edades infantiles (véase la figura 1), ilustra muy bien el efecto de los patrones socioculturales, en este caso cristalizados en la noción de género, sobre el perfil de mortalidad. En principio no parece que haya nada biológico que haga que los varones tengan predisposición a morir por LT.

\section{Lesiones no mortales y discapacidad}

A pesar de que la información es muy fragmentaria, los datos muestran que las LT constituyen en muchos países una de las causas principales de demanda de atención médica, hospitalización y discapacidad permanente. En los Estados Unidos hubo en 1992 unos 5 millones de lesionados, $1,9 \%$ de la población, con medio millón de hospitalizaciones (39). En 1989 el tráfico causó en el Brasil unos 450000 lesionados, de los que unos 50000 fallecieron (31). En España 1,1\% de la población tuvo que ser atendida en 1993 en servicios de urgencias y $1,2 \%$ requirió algún tipo de atención sanitaria (20). Según estimaciones de la OMS, por cada adolescente que muere debido a LT, entre 10 y 15 quedan con secuelas graves y entre 30 y 40 sufren heridas que exigen atención urgente o rehabilitación (40). En los llamados países "en desarrollo" se estima que anualmente el tráfico produce lesiones a una de cada 150 personas (35).

La lesión provocada por el choque afecta muchas veces al sistema nervioso y a menudo genera paraplejía, tetraplejía u otro tipo de trastorno neurológico permanente. En los Estados Unidos se estimó que cada año se producen unos 20000 nuevos casos de epilepsia como consecuencia de LT (25). Dado que las víctimas son a menudo jóvenes, las secuelas neuroló- gicas de las LT suponen muchos años de vida discapacitada y cargas consiguientes por la atención personal necesaria. En 1981 la Oficina Regional de la OMS para Europa (27) estimó que había en el mundo unos 30 millones de personas con discapacidad permanente debida a LT.

\section{Volumen de tráfico e incidencia de lesiones}

Si como medida de la peligrosidad del tráfico se utiliza una tasa anual de defunciones según el número de vehículos, tanto en estudios transversales como en estudios longitudinales esa tasa disminuye a lo largo del tiempo o, transversalmente, al aumentar el índice de motorización $(27,34)$. Así en 1978 la tasa de mortalidad por vehículo fue en Etiopía o en Nigeria unas 50 veces mayor que en los Estados Unidos o el Reino Unido (27). Esta relación fue descrita por Reuben Smeed en 1949 y por ello se ha denominado "ley de Smeed" (16).

A efectos de salud pública, más que la mortalidad respecto al número de vehículos (que es algo así como la tasa de cáncer de pulmón por mil cigarrillos fumados) lo que interesa es el volumen total de mortalidad y morbilidad y las tasas poblacionales correspondientes. Esas tasas aumentaron rápidamente en todos los países en las primeras fases de crecimiento del parque automovilístico. Al llegarse a cotas altas de motorización, el crecimiento de las tasas de mortalidad por LT se hizo más lento y finalmente la tasa se estabilizó o incluso disminuyó en diversos países (41). En los Estados Unidos la mortalidad por LT llegó a un máximo en 1972 (casi 57000 defunciones) y luego disminuyó poco a poco, siempre con fuertes oscilaciones. Desde 1960 nunca bajó de 40000 defunciones anuales y periódicamente repunta en los períodos de reactivación económica (figura 2).

Tal como mostró Eyer $(42,43)$, la mortalidad por LT fluctúa con los ciclos económicos: disminuye en los períodos de recesión y aumenta en los de expansión (9). Las gráficas de mor- 
FIGURA 1. Tasas anuales de mortalidad específicas por sexo, por grupo decenal de edad y por millón de personas, debidas a lesiones de tráfico (--), homicidio $(-+-)$ y tuberculosis (-- --$)$. Datos de ocho países, ordenados de menor a mayor índice de motorización (IM, en automóviles por 1000 habitantes). La escala del eje Y difiere de unos gráficos a otros, por lo que cualquier comparación debe tener en cuenta dicha escala
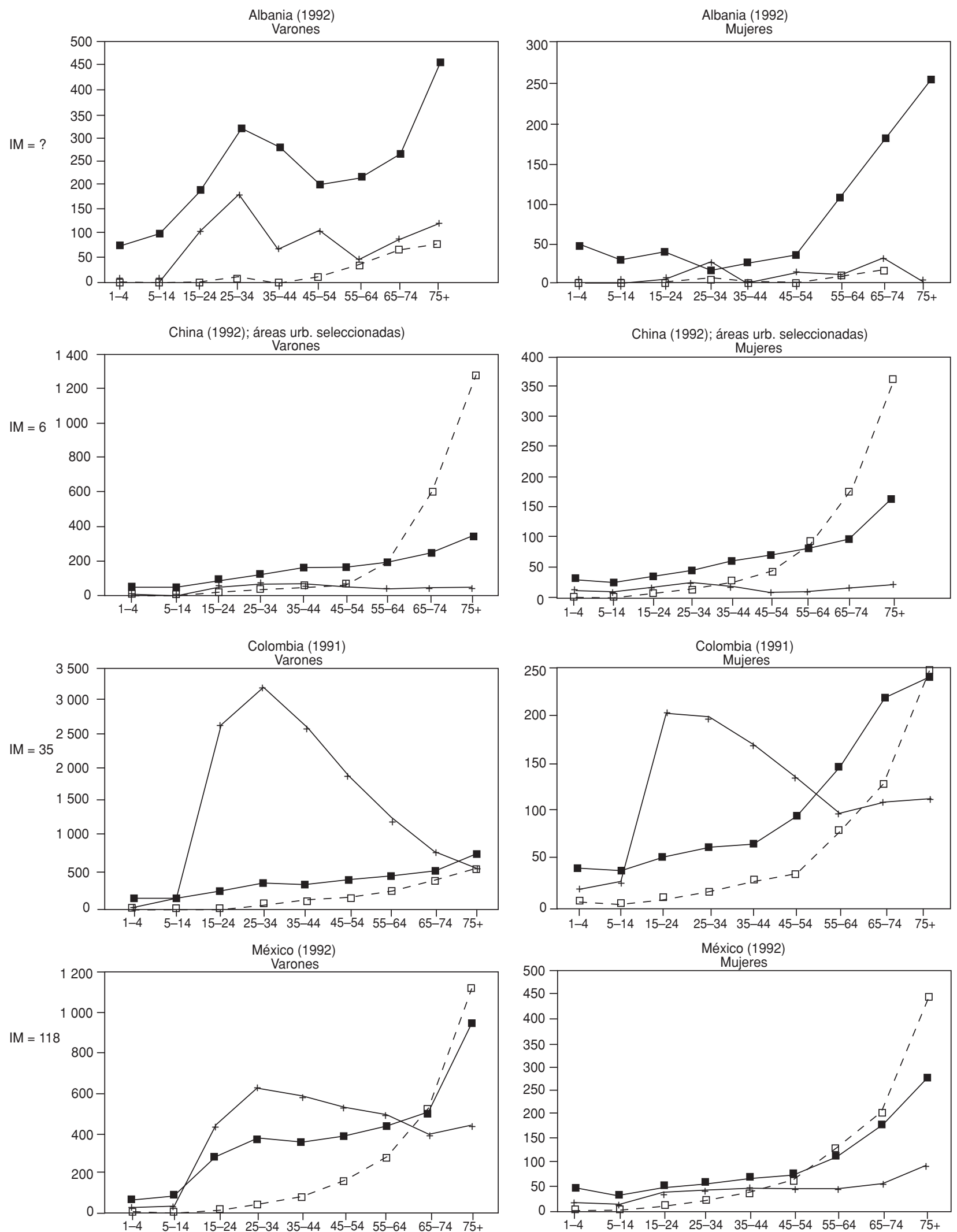
FIGURA 1. (Continuación)
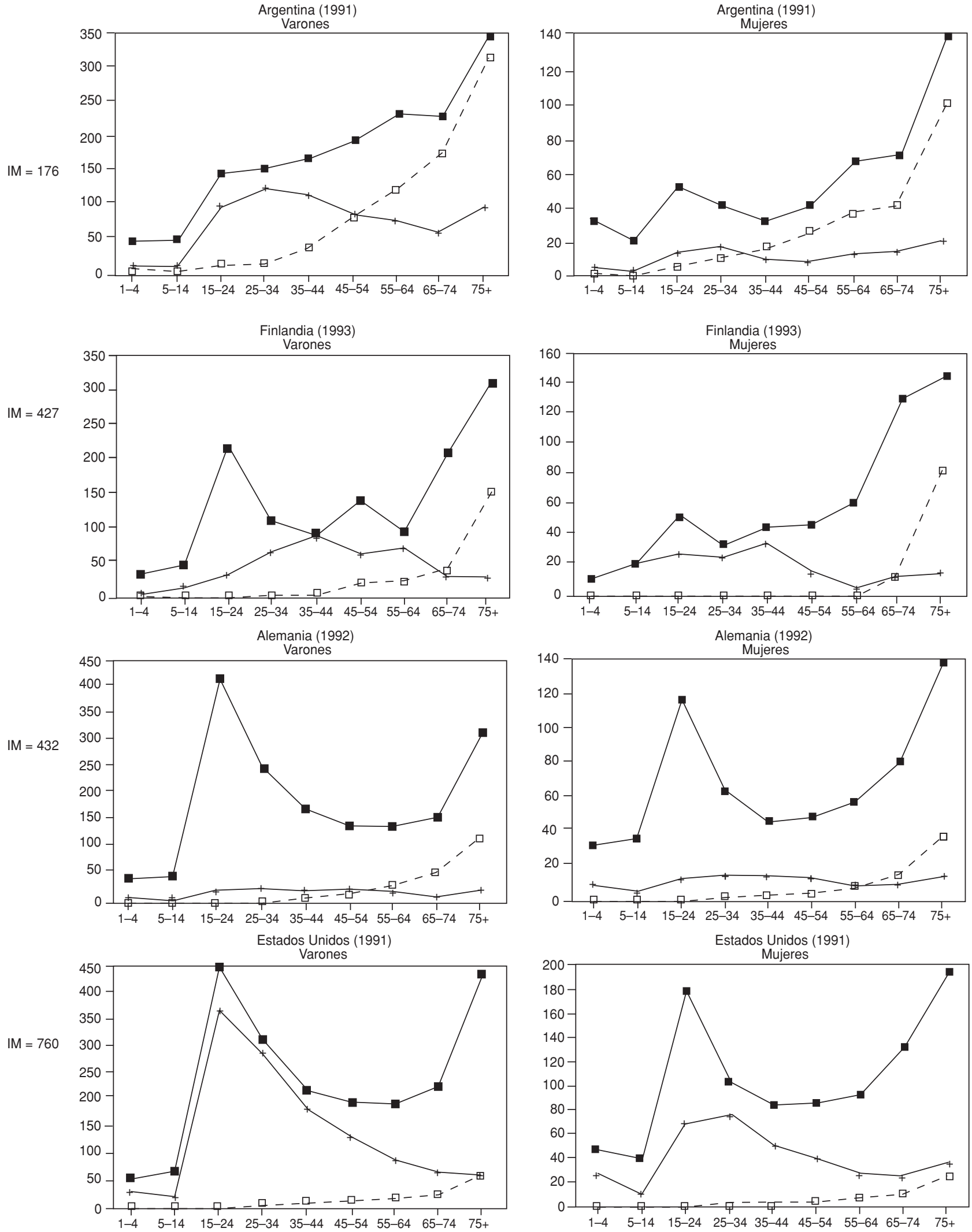

Fuente: OMS (ref. 38, cuadro B1). 
FIGURA 2. Tasa de mortalidad anual por lesiones de tráfico (por 100000 habitantes) y porcentaje de desempleo (en la población activa) de los Estados Unidos, 1951-1994. Las lesiones de tráfico y la mortalidad correspondiente aumentan en los períodos de expansión económica en los que disminuye el desempleo y hay más circulación de vehículos y más consumo de alcohol; inversamente, disminuyen en los períodos de recesión. Véanse más detalles en el texto

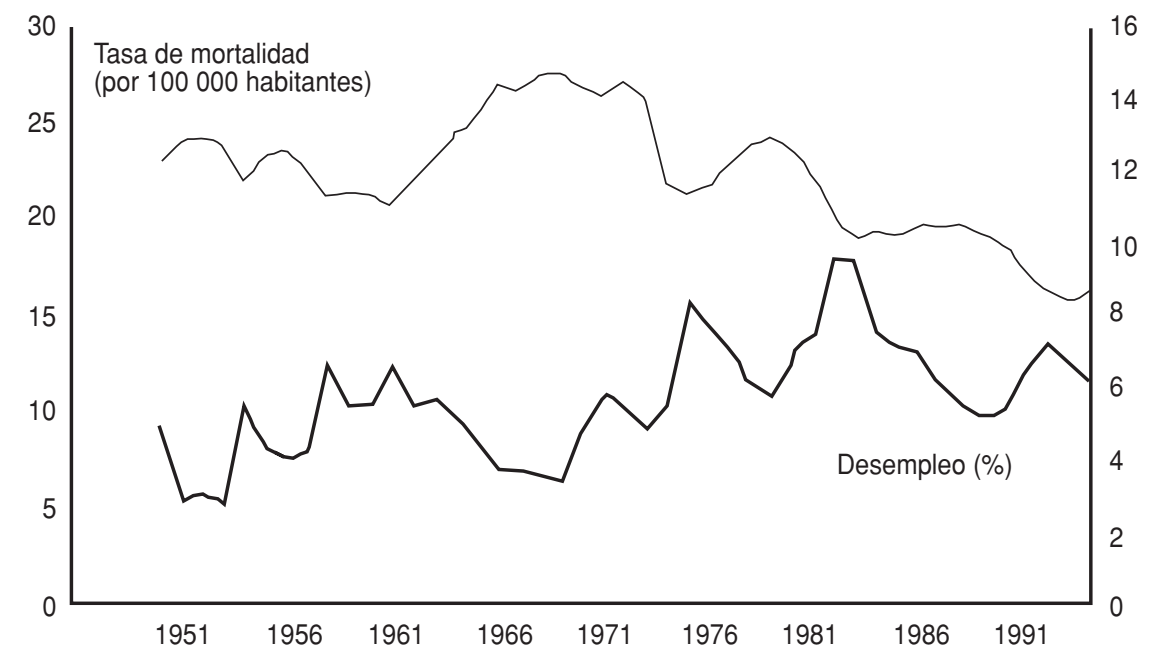

Fuentes: Varias ediciones del Handbook of labor statistics (US Bureau of Labor, Department of Commerce) y del Statistical abstracts of the United States (US Department of Commerce, Bureau of the Census).

talidad por LT o de siniestros automovilísticos muestran una imagen en espejo respecto al porcentaje de desempleo (véase la figura 2). Uno de los factores mediadores de esta relación sería precisamente el volumen de tráfico, que disminuye considerablemente en las recesiones y aumenta en los períodos de reactivación. El mayor consumo de alcohol en los períodos de expansión económica puede intervenir también en esta relación tan llamativa (43).

En estudios transversales las tasas de colisiones y de mortalidad por LT muestran una relación directa con la densidad del tráfico (44) y con el producto nacional bruto (34), que tiene una alta correlación con dicha densidad. En series temporales se encuentra también una relación directa entre las variaciones del volumen de tráfico $\mathrm{y}$ de la tasa de defunciones infantiles por atropello (45). Estos datos son coherentes con la caída de la mortalidad por LT que se observa en períodos en los que hay una intensa reducción del tráfico, como ocurrió a continuación de la guerra del Yom Kipur (1973), que desencadenó el embargo de petróleo de los países árabes, el aumento de precios y el racionamiento de los combustibles y en muchos países fue el inicio de una recesión económica importante. En 1974 las LT causaron en los Estados Unidos algo más de 46000 defunciones, casi 10000 menos que en 1973. La velocidad máxima en autopistas se redujo en 1974 a 55 millas por hora $(88,5 \mathrm{~km} / \mathrm{h})$ como medida de ahorro de combustible (19), lo cual probablemente también tuvo un efecto importante en la reducción de la mortalidad (9). En la República Federal de Alemania las defunciones por LT se redujeron aproximadamente a la mitad de 1973 a 1974, muy posiblemente por causas similares (46).

El precio del combustible repercute en la tasa de mortalidad por LT mediante su relación con el volumen de tráfico. A menor precio, mayor tráfico y mayor número de muertes por LT (18). En 1980 el único país de América Latina con una tasa de mortalidad por LT mayor que la de los Estados Unidos fue Venezuela (27), donde la gasolina cuesta alrededor de 10 veces menos que en los Estados Unidos.
En Asia, África y América Latina, el crecimiento continuo del número de automóviles en ciudades densamente pobladas llevó a algunos autores a pronosticar un aumento rápido de la carga de defunciones, heridos y discapacidades por LT (47). De hecho, entre 1968 y 1983, la mortalidad por LT aumentó más de $200 \%$ en África y cerca de $150 \%$ en Asia (34). En Tailandia aumentó casi 30\% todos los años entre 1947 y 1982 (35). Que en un país como Arabia Saudí la construcción de carreteras y el aumento vertiginoso del número de automóviles coincidieran con un alza del $600 \%$ de la mortalidad y la mortalidad por LT (35) indica claramente que la peligrosidad del tráfico no es un problema de falta de recursos para vehículos modernos e infraestructuras viarias.

En América Latina la mortalidad por LT se mantuvo más o menos constante durante los años ochenta (48), período en el que la crisis económica probablemente limitó en gran medida la motorización y el tráfico. Quizá la "década perdida" supuso así un "ahorro" de miles de defunciones y discapacitados en colisiones que no se produjeron.

\section{El tráfico como factor de riesgo para los usuarios del espacio público}

Caminar o desplazarse en bicicleta o en un vehículo de tracción animal es en sí poco peligroso, pero hacerlo en calles o carreteras en las que circulan automóviles comporta un riesgo de lesión muy alto. Según datos del Reino Unido (49), el riesgo de muerte por hora invertida en transporte es para un peatón más del doble que para un automovilista. Para un ciclista es más del quíntuplo (cuadro 2). Vistos los datos de diversos países, es probable que a nivel mundial la mayor parte de las víctimas de LT sean peatones y ciclistas. Según la OMS, en dos terceras partes de las colisiones que producen víctimas, algunas de estas son peatones, casi siempre niños (50). Entre 1990 y 1994, los atropellos causaron $43 \%$ del total de defunciones por LT en Costa Rica; las colisiones entre automóviles, solo $23 \%$ (51). En el Brasil 90\% de los que sufren LT 
son víctimas de atropellos. Estos originan $50 \%$ del total de hospitalizaciones por LT, son la categoría más frecuente de defunción por LT en el país y producen $85 \%$ de las defunciones por LT en Rio de Janeiro $(30,31)$. En Irak 55\% de los muertos por LT son peatones (34) y en la India, $95 \%$ de los muertos por LT en años recientes fueron peatones $o$ ciclistas (52).

En la mayor parte del mundo los desplazamientos cotidianos se hacen a pie, en transporte público o en bicicleta y los automóviles generan un riesgo enorme para la población. A menudo se buscan soluciones "al problema del tráfico" mediante la construcción de infraestructuras viarias, la mejora de los vehículos y los dispositivos de seguridad (cinturones, cascos, material reflectante, uso diurno de luces, etc.). Sin embargo, algunas de esas medidas "técnicas" no solo aumentan el volumen de tráfico y los problemas de congestión (53) sino que pueden incrementar el riesgo para peatones, ciclistas y otros usuarios de la vía pública. La eliminación de semáforos y el ensanchamiento de las calles para dar fluidez al tráfico aumentan el riesgo de atropellos y colisiones. Aunque es un tema muy disputado $(9,10)$, algunos autores consideran que dispositivos de seguridad como el cinturón, las bolsas de aire antichoque o los frenos antibloqueo pueden generar el fenómeno denominado compensación de riesgo. El conductor de un vehículo equipado con estos dispositivos puede sentirse más seguro y arriesgarse más, conduciendo a mayor velocidad y con menos precaución, lo cual incrementa la probabilidad de siniestro (16).

En los Estados Unidos han muerto alrededor de un centenar de personas, la mitad de ellos niños, por la expansión de la bolsa de aire en choques a poca velocidad que probablemente no habrían tenido consecuencias en un vehículo sin bolsa de aire (54). Como los partidarios del airbag dicen que este dispositivo ha evitado cientos de muertes en colisiones a alta velocidad, se plantea el problema moral de un artefacto que salva centenares de vidas a costa de matar a decenas de personas. Por otra parte, según estadísticas

\section{CUADRO 2. Mortalidad durante el transporte de personas en diferentes medios, según datos del Reino Unido}

\begin{tabular}{lcc}
\hline \multicolumn{1}{c}{$\begin{array}{c}\text { Medio de } \\
\text { transporte }\end{array}$} & $\begin{array}{c}\text { Defunciones por } 10^{8} \\
\text { horas-viajero }\end{array}$ & $\begin{array}{c}\text { Defunciones por } 10^{8} \\
\text { kilómetros-viajero }\end{array}$ \\
\hline Autobús & 1,4 & 0,06 \\
Tren o tranvía & 6 & 0,1 \\
Automóvil & 12,4 & 0,4 \\
Transporte acuático & 16 & 0,8 \\
Transporte aéreo & 20 & 0,04 \\
Marcha a pie & 27 & 7,0 \\
Bicicleta & 64 & 4,6 \\
Motocicleta & 342 & 11,4 \\
\hline
\end{tabular}

Fuente: Evans (49).

preliminares de la National Highway Transportation Safety Administration la mortalidad por LT de los ocupantes adultos de automóviles equipados con bolsas de aire es mayor que la de quienes viajan en automóviles sin dicho dispositivo (55). Esto sería un ejemplo típico de compensación de riesgo.

Muchas de las políticas de seguridad viaria consisten en dotar a los automóviles de espacio propio (las autopistas y "autovías" son el ejemplo más claro) del que son excluidos los demás usuarios, que son obligados a usar vías públicas secundarias para circular o a cruzar las carreteras por pasos elevados o subterráneos. Ejemplo de esa tendencia es la reciente prohibición de la circulación de bicicletas en muchas calles y carreteras de China (56). A medida que aumenta el tráfico, el espacio público se hace más inseguro y más molesto para circular en bicicleta, caminar, pasear o jugar (16). La reciente disminución de la mortalidad de peatones y ciclistas en varios países ha sido interpretada por varios autores $(16,57)$ no como una mejora de la seguridad vial sino como un indicio de la creciente expulsión de estos usuarios del espacio público transitable.

El riesgo de lesiones que genera el tráfico no se distribuye aleatoriamente entre las clases sociales. Como otras muchas causas de enfermedad o muerte, las LT repercuten especialmente en los pobres y las minorías marginadas. En niños negros menores de 10 años de los Estados Unidos, la tasa de mortalidad por atropello entre 1980 y 1985 fue más del doble que en blancos (14). En el Reino Unido la mortalidad por LT en varones adultos de las clases sociales IV y V fue $84 \%$ mayor que en las clases I y II (en la clasificación de cinco clases sociales que suele usarse en ese país) (53). Los niños de la clase social $\mathrm{V}$ sufren siete veces más LT que los de la clase I (58). Además, en los estratos de bajo ingreso no solo son más frecuentes las defunciones o las LT no mortales, sino que, una vez producida la lesión, el pronóstico es peor y la letalidad mayor por las diferencias de tratamiento quirúrgico (57).

\section{Morbilidad y mortalidad por mecanismos no lesionales}

Los vehículos de motor son la fuente principal de emisiones contaminantes de efectos locales y continentales y a ellos corresponde más de tres cuartas partes de la contribución del sector del transporte a la contaminación atmosférica mundial (52). Debido principalmente al tráfico, más de 1000 millones de residentes en grandes metrópolis sufren niveles de contaminación considerados inadmisibles por la OMS (50, 59). Las megaciudades de Asia y América Latina son precisamente las de mayor contaminación atmosférica del mundo $(52,60)$. En las capitales de México y de Chile se han declarado ya varios estados de emergencia por la contaminación (40). 
Desde el episodio londinense de alta contaminación atmosférica en diciembre de 1952 al que se atribuyen entre 3500 y 4000 defunciones, se sabe que la contaminación, especialmente las partículas en suspensión y el dióxido de azufre $\left(\mathrm{SO}_{2}\right)$, aumenta la mortalidad por enfermedades respiratorias y cardiovasculares. Las investigaciones de la relación entre mortalidad o morbilidad y contaminación atmosférica muestran una relación lineal sin umbral, como en el tabaquismo. No parece haber un nivel mínimo por debajo del cual la contaminación atmosférica no tenga efectos nocivos (61-63).

En seis ciudades estadounidenses se halló una relación directa entre la contaminación atmosférica y la mortalidad general y específica por enfermedades cardiovasculares y por cáncer de pulmón. La tasa de mortalidad general de la ciudad más contaminada fue $26 \%$ mayor (intervalo de confianza del $95 \%$ : $8 \%$ a $47 \%$ ) que la de la menos contaminada (64). En América Latina se ha comprobado el incremento de la mortalidad general relacionado con la contaminación atmosférica en Santiago, Chile, (65) y en São Paulo, Brasil (66). Según datos de París, la tasa de mortalidad por enfermedades cardiovasculares sufre incrementos de hasta $6 \%$ a medida que aumentan los niveles medios diarios de partículas sólidas en suspensión (63).

La exposición a productos de la combustión - principalmente partículas en suspensión, compuestos sulfurosos $\left(\mathrm{SO}_{2}, \mathrm{SO}_{3}\right)$, óxidos de nitrógeno $\left(\mathrm{NO}_{\mathrm{x}}\right)$, ozono $\left(\mathrm{O}_{3}\right)$ y monóxido de carbono (CO) - genera una disminución de los parámetros funcionales respiratorios y el aumento de la frecuencia de síntomas respiratorios, ataques de asma y conjuntivitis $(40,67)$. En escolares de la ciudad de México y en Santiago, Chile, se ha hallado una elevación significativa del riesgo de tos y otros síntomas respiratorios y absentismo escolar, y en Santiago se ha estimado un exceso anual de 35000 casos de asma y 50000 de neumonía debidos a la contaminación (40). Autores catalanes hallaron en Barcelona una relación directa entre el número de consul- tas hospitalarias de urgencia - como consecuencia del agravamiento de enfermedades respiratorias crónicasy el nivel de contaminación atmosférica (61). El mismo fenómeno se ha observado en la ciudad de México, en Los Ángeles y en Londres (53). En estadounidenses menores de 25 años han aumentado las tasas de hospitalización y mortalidad por asma, fenómeno que podría estar relacionado con la contaminación, sobre todo por $\mathrm{O}_{3}(68)$.

Los compuestos aromáticos policíclicos generados por la combustión podrían ser responsables de la mayor incidencia de neoplasias malignas en las zonas urbanas (50). Varios estudios en países europeos en los que se tuvo en cuenta el efecto del tabaquismo y la contaminación ambiental mostraron resultados muy sugerentes de que la densidad de tráfico es un factor importante de riesgo de cáncer $(64,69)$.

La combustión de la gasolina con plomo origina todavía en muchas ciudades más de $90 \%$ del plomo inhalable (52) cuyo efecto crónico son trastornos neurológicos en adultos y alteraciones del desarrollo psicológico en niños. En embarazadas la exposición a CO se asocia con bajo peso al nacer y retraso del desarrollo posnatal (59).

El ruido debido al tráfico no solo provoca molestias subjetivas. Cuando solo o asociado con otras causas llega a ciertos niveles, causa sordera, deterioro del rendimiento psicofísico y aumento de la agresividad. El ruido nocturno al que subjetivamente las personas creen habituarse sigue provocando respuestas cardiovasculares tras 5 años de exposición (50). La exposición continua a ruido de tráfico aumenta la frecuencia cardíaca, la tensión arterial y la secreción de adrenalina, todo lo cual puede llevar a hipertensión crónica y cardiopatía (58). En muchas ciudades con alta densidad de población, nivel elevado de motorización $y$, a menudo, deterioro importante de los vehículos y falta de respeto a las normas, el ruido del tráfico empeora significativamente la calidad de vida. A las bocinas y el ruido generado por la circulación misma se han añadido recientemente las alarmas antirrobo, cuya molesta y frecuente activación conocen ya probablemente la mayoría de los habitantes del medio urbano.

\section{La carga total de morbilidad y mortalidad atribuibles al tráfico}

Cuantificar conjuntamente la morbilidad y la mortalidad debidas a una causa exige diversos supuestos, muchos de ellos muy débiles. Las estimaciones a menudo se basan en cálculos "a ojo". Estimar, por ejemplo, la pérdida de "años de vida ajustados según discapacidad" (AVAD) exige sumar pérdidas reales de vidas humanas "completas" (de quienes mueren), y pérdidas parciales hipotéticas (de vida) de los que viven enfermos o lesionados. Ello obliga a la peligrosa operación intelectual de equiparar un año de vida ciego o parapléjico a un porcentaje arbitrario de un año de vida "completamente sana". A pesar de esas dificultades y a pesar de que, según la OMS (33), en muchos países ni siquiera existen registros mínimamente fiables de causas de defunción, en un informe reciente preparado para el Banco Mundial $(32,70,71)$ se estimó la "carga global de enfermedad" correspondiente al total de pérdida de salud - por decirlo de alguna manera- debida a muerte, enfermedad o discapacidad por distintas causas. Según los resultados finales del informe (71), ${ }^{3}$ en 1990 las LT fueron responsables en todo el mundo de 2,5\% del total de AVAD perdidos, lo cual las sitúa por orden de importancia como novena causa de morbilidad y mortalidad, por delante del paludismo $(2,3 \%)$ y del sida $(0,8 \%)$, y por detrás de la tuberculosis $(2,8 \%)$, la cardiopatía isquémica $(3,4 \%)$ y las enfermedades diarreicas $(7,2 \%)$. En las regiones "demográficamente desarrolladas" (según terminología de Murray y Lopez), las LT son responsables de $4,4 \%$ de los AVAD perdidos, lo que las

\footnotetext{
3 El porcentaje de pérdida total de AVAD atribuido a distintas causas difiere considerablemente en distintas versiones del informe (véanse ref. 68, p. 269, y ref. 67, p. 509, en el Bull World Health Organ)
} 
sitúa en cuarto lugar tras las enfermedades cerebrovasculares $(5,9 \%)$, la depresión unipolar $(6,1 \%)$ y la cardiopatía isquémica $(9,9 \%)$. En el resto del mundo las LT ocupan el undécimo puesto como causa de pérdida de vida sana, con $2,2 \%$ del total de AVAD perdidos, por detrás de la tuberculosis $(2,5 \%)$ y el paludismo $(2,4 \%)$, muy por delante del sida $(0,8 \%)$.

En el grupo de 15 a 44 años de edad, ambos sexos considerados, las LT son a nivel mundial la tercera causa de pérdida de AVAD. Si se tiene en cuenta solamente a los varones, son la segunda causa, tanto en las regiones industrializadas como en el resto del mundo (71).

Si estas estimaciones asignan a las LT un peso enorme en la carga global de morbilidad y mortalidad, otras estimaciones parecen asignarles un peso incluso mayor. En Tailandia, Malasia y Singapur, por sí solas, las defunciones por LT generan más años de vida potencial perdidos que la tuberculosis y el paludismo combinados (29).

De todas formas, las estimaciones de morbilidad y mortalidad mencionadas se refieren solamente a la vida o la salud perdida como consecuencia de muertes o discapacidades producidas por los mal llamados "accidentes" y no incluyen las enfermedades cardiovasculares y respiratorias, los trastornos psiconeurológicos y las neoplasias malignas atribuibles al tráfico. Las cardiopatías, el cáncer y las enfermedades respiratorias están entre las cuatro primeras causas de muerte en casi todos los países y las enfermedades respiratorias son la primera causa de morbilidad medida en jornadas de trabajo perdidas. Por ello, un incremento incluso pequeño de la morbilidad y mortalidad por estas causas (y según estimaciones como las de Dockery et al. (64) y Medina et al. (63) no es excesivo pensar que ese aumento bien puede ser de 5 a 10\% como mínimo) supondría una enorme carga total de enfermedad atribuible al tráfico. Los efectos nocivos de la motorización no se perciben en su totalidad cuando se miden solo en función de las lesiones y los muertos por colisiones y no se tienen en cuenta las enfermedades y el deterioro de la calidad de la vida generados por la contaminación y el ruido.

\section{El tráfico como contribuyente al efecto invernadero}

El Grupo Intergubernamental de Expertos sobre Cambios Climáticos (IPCC según sus iniciales en inglés) se constituyó en 1988, respaldado por el Programa de las Naciones Unidas para el Medio Ambiente y la Organización Meteorológica Mundial. Según su segundo informe (1995), ${ }^{4}$ en cuya preparación participaron unos 2500 científicos, las actividades humanas desde el comienzo de la revolución industrial han hecho aumentar significativamente las concentraciones atmosféricas de $\mathrm{CO}_{2}$, metano $\left(\mathrm{CH}_{4}\right)$ y óxido nitroso $\left(\mathrm{N}_{2} \mathrm{O}\right)$. Como consecuencia, la temperatura media de la superficie atmosférica ha aumentado entre $0,3 \mathrm{y}$ $0,6{ }^{\circ} \mathrm{C}$ desde finales del siglo XIX y ha habido un alza del nivel del mar de aproximadamente 10 a $25 \mathrm{~cm}$ en los últimos 100 años, en gran parte atribuible al efecto invernadero y el consiguiente calentamiento atmosférico. Si las emisiones de $\mathrm{CO}_{2}$ se mantuvieran a los niveles de 1994, la concentración atmosférica de $\mathrm{CO}_{2}$ sería a final del siglo XXI aproximadamente el doble de la correspondiente a tiempos preindustriales. Para esa fecha el aumento de la temperatura media de la superficie atmosférica se estima en unos $2{ }^{\circ} \mathrm{C}$. El nivel del mar seguirá en alza durante varios siglos y provocará la inundación de las zonas costeras bajas y la desaparición de algunos países insulares. Serán más frecuentes las temperaturas extremas, las inundaciones, las sequías y las tormentas, todo lo cual podría provocar serios trastornos de la agricultura.

El IPCC subraya que hay mucha incertidumbre en esas predicciones,

\footnotetext{
4 En el sitio del IPCC en el WWW (http://www. unep.ch/ipcc/syntrep/html) se encuentran extensos resúmenes de la documentación del segundo informe del IPCC. El informe completo está publicado en tres volúmenes por Cambridge University Press.
}

pero advierte también que hay pruebas claras de que el clima está cambiando por influencia humana y que, dada la naturaleza compleja del sistema climático, la probabilidad de cambios rápidos importantes se incrementa cuando se fuerzan rápidamente sus condiciones de funcionamiento (72). Aparte de las consecuencias para la salud de los desastres "naturales" y el deterioro de la producción agrícola, el cambio climático probablemente puede repercutir inmediatamente en un aumento de la incidencia de paludismo — con un alza del número de defunciones anuales hasta de un millón-, dengue, encefalitis vírica y otras enfermedades infecciosas (73).

Las advertencias del IPCC concuerdan con fenómenos climáticos recientes que podrían ser las primeras señales del cambio. En los últimos años han sido frecuentes en todo el mundo las sequías prolongadas, las tormentas desastrosas y otros fenómenos atmosféricos "raros" (72), uno de los cuales fue el ciclón que en mayo de 1991 arrasó Bangladesh provocando 140000 muertes y pérdidas materiales estimadas en más de 10\% del PNB del país, en resumen, uno de los peores desastres "naturales" de los últimos tiempos (56). En años recientes, los seguros han tenido que pagar compensaciones por desastres climáticos con mucha más frecuencia que en épocas anteriores y la industria de los seguros se ha interesado seriamente en los cambios de clima (74).

En 1992 en la Conferencia de las Naciones Unidas sobre el Medio Ambiente y el Desarrollo, se acordó que al llegar el año 2000 se habrían estabilizado las emisiones de $\mathrm{CO}_{2}$ al nivel de 1990. Para frenar efectivamente el calentamiento atmosférico, las emisiones de $\mathrm{CO}_{2}$ deberían reducirse en $60 \%$. Sin embargo, es de esperar que el incremento del transporte aumente esas emisiones. Según estimaciones del IPCC, el transporte contribuyó en 1990 con $21 \%$ del total, la industria con $45 \%$ y el sector residencial-comercial con $29 \%$ de las emisiones de $\mathrm{CO}_{2}$. En los últimos 20 años, las del transporte han crecido más rápidamente que las de los otros dos sectores (74). 
En muchos países la demanda de transporte de carga y pasajeros se ha satisfecho casi exclusivamente por el aumento del número de camiones y automóviles, tendencia especialmente aguda en los países de Europa Oriental y China (52). Según un informe del gobierno británico publicado en 1996, la cantidad anual de kilómetrospasajero recorridos en el Reino Unido prácticamente se dobló desde 1970. El consumo industrial y comercial de energía se redujo $40 \%$ en ese período, pero a pesar de contar con mejores motores y diseños más eficientes de vehículos, el consumo automovilístico de combustible aumentó 100\% (75). Una comisión gubernamental consideró imposible que el país reduzca sus emisiones de $\mathrm{CO}_{2}$ sin atajar el crecimiento del transporte, en concreto el uso de automóviles privados (76).

Las emisiones de $\mathrm{CO}_{2}$ dependen directamente del tráfico y cada vehículo que circula contribuye a agravar el efecto invernadero. La distribución de los automóviles según la población (véase el cuadro 1) indica claramente las repercusiones que tendría sobre la emisión mundial de $\mathrm{CO}_{2}$ una motorización de China similar a la de los Estados Unidos. La tendencia al aumento del comercio internacional (la llamada "globalización" o "mundialización" de la economía) puede intensificar aun más la contribución del transporte al efecto invernadero.

\section{La motorización del medio urbano}

Actualmente la mitad de la población mundial vive en ciudades. Estas pueden clasificarse básicamente en tres tipos (cuadro 3). En Asia y África predominan las ciudades peatonales, de alta densidad de población y baja motorización, en las que el medio principal de transporte es la marcha a pie. En Europa y América Latina predominan ciudades de menor densidad de población en las que el transporte colectivo en autobuses y trenes suburbanos es el más frecuente. En los Estados Unidos predomina la ciudad de automóviles, de bajísima densidad de población y escaso transporte público (77).

CUADRO 3. Tipos de ciudades según la densidad de población y el transporte predominante

\begin{tabular}{lcccc}
\hline & $\begin{array}{c}\text { Densidad urbana } \\
\text { en personas } \\
\text { por hectárea } \\
\text { (promedio) }\end{array}$ & $\begin{array}{c}\text { Automóviles } \\
\text { por } 1000 \\
\text { personas }\end{array}$ & $\begin{array}{c}\text { Consumo anual } \\
\text { de gasolina } \\
\text { (kg/persona) }\end{array}$ & $\begin{array}{c}\text { Uso anual del } \\
\text { transporte público } \\
\text { (viajes per cápita) }\end{array}$ \\
\hline $\begin{array}{l}\text { Ciudades de } \\
\text { automóviles }\end{array}$ & $\begin{array}{c}10 \text { a } 30 \\
(20)\end{array}$ & 400 & 870 & 90 (bajo) \\
$\begin{array}{c}\text { Ciudades de } \\
\text { transporte público }\end{array}$ & $\begin{array}{c}30 \text { a } 130 \\
(90)\end{array}$ & 170 & 220 & 310 (alto) \\
$\begin{array}{c}\text { Ciudades de } \\
\text { transporte peatonal }\end{array}$ & $\begin{array}{c}130 \text { a } 400 \\
(170)\end{array}$ & 20 & 60 & 180 (medio) \\
\hline
\end{tabular}

Fuente: Newman y Kenworthy (77).

Hasta el siglo XIX las ciudades en todo el mundo eran de alta densidad demográfica, ya que la marcha a pie era casi el único medio de transporte. Durante el siglo XX el transporte público las hizo expandirse, sobre todo en los países industrializados, donde la generalización del automóvil provocó una dispersión ulterior. En Europa las ciudades crecieron a partir de cascos urbanos más o menos estructurados, en los que el crecimiento del parque vehicular llevó a grandes congestiones de tráfico $\mathrm{y}$, sucesivamente, a múltiples y costosas obras públicas de efecto transitorio, anulado por el constante aumento de automóviles.

En los Estados Unidos muchas zonas urbanas surgieron prácticamente a la vez que el automóvil y la baja densidad de población disminuyó aun más con el desarrollo de zonas suburbanas. De las 25 ciudades estadounidenses más pobladas en 1950, 18 perdieron población en los decenios siguientes. Saint Louis pasó de 857000 habitantes en 1959 a 397000 en 1990 $(78,79)$. La huida de las clases media y alta de los centros urbanos hizo que los interiores de las ciudades (inner cities) quedaran restringidos a clases trabajadoras de bajos ingresos. Muchas partes del centro urbano se convirtieron en barrios fantasma, en los que la maleza crece entre casas abandonadas y donde el tráfico de drogas $\mathrm{u}$ otras actividades ilegales dan salida al desempleo y la depauperación social. En la periferia crecieron los suburbs, zonas de viviendas unifamiliares dispersas. Esta infraestructura urbana dispersa exige gastos mucho mayores en transporte e implica grandes inversiones en pavimentación, conexiones telefónicas, alcantarillado y sistemas de abastecimiento de agua y electricidad. Por otra parte, ese tipo de desarrollo urbano dificulta la creación de vínculos comunitarios, ya que la baja densidad de población y la falta de espacios peatonales impide cultivar las relaciones personales y la vida callejera en el vecindario, en la que surgen amistades y lazos humanos $(18,78)$. Tanto en los suburbs como en las inner cities, las grandes distancias, la escasez de transporte público, la desaparición de pequeños comercios en las zonas residenciales y su sustitución por grandes almacenes en las autopistas hacen prácticamente obligatorio tener automóvil. En promedio, cada estadounidense pasa más de una hora diaria en un automóvil, en parte considerable detenido en atascos. Como varias personas del núcleo familiar suelen desplazarse diariamente, dada la escasez del transporte público, cada uno de ellos necesita un vehículo. La posesión de más de un automóvil por familia, de un lujo pasa a ser una necesidad (80). La proporción de hogares con dos o más vehículos en 1960 no pasaba de $10 \%$, pero se aproximó a $60 \%$ en 1990. Los Ángeles, donde dos terceras partes de la superficie urbana están dedicadas al uso de los automóviles (frente a menos de 
$10 \%$ en muchas ciudades asiáticas y de 20 a $25 \%$ en las europeas), es el ejemplo más evidente de los efectos de la planificación urbana en función del automóvil. En un estudio de 29 ciudades estadounidenses, Los Ángeles reveló la peor congestión de tráfico y mayores costos per cápita como resultado (53). En cuanto a contaminación atmosférica, a pesar de que en los años ochenta el estado de California promulgó las leyes más severas del país para prevenir las emisiones, en 19911993 Los Ángeles fue la ciudad estadounidense con peores niveles de contaminación y un promedio anual de más de 100 días en los que se violaron los estándares nacionales de calidad del aire (81).

Excepto en los Estados Unidos y Australia, las ciudades siguen siendo de alta densidad y el transporte que predomina en ellas es el colectivo, o a pie o en bicicleta. Sin embargo, el rápido crecimiento del parque de vehículos privados ha creado problemas de tráfico y contaminación prácticamente en todas las zonas urbanas (52, 82). Yakarta, El Cairo, Buenos Aires, México, São Paulo, Atenas, París y Varsovia son solo algunas de las muchas ciudades en las que los atascos y la contaminación son problemas cotidianos. En Bangkok la velocidad media del tráfico es $10 \mathrm{~km} / \mathrm{h}$, promedio que se reduce a 5 ó $6 \mathrm{~km} / \mathrm{h}$ (la velocidad a la que camina un peatón) en las horas punta (52).

El automóvil tiene la indiscutible ventaja de constituir un espacio aislado que protege de las interacciones no deseadas. Además de ser un símbolo de status, sobre todo cuando la mayoría no lo posee, el espacio cerrado del automóvil genera una sensación de seguridad en muchas personas. En las ciudades donde las diferencias sociales son abismales y la riqueza convive con la marginación y el hambre, el automóvil permite el transporte personal "seguro" a través de áreas "peligrosas". Sin embargo, los efectos acumulativos son perversos. A medida que aumenta la circulación de automóviles, las calles se hacen más solitarias. Los niños dejan de ir caminando o en bicicleta a la escuela y se les lleva en auto- móvil "para evitar riesgos", con lo cual pierden ocasiones de contacto social. El mayor uso del automóvil incrementa el riesgo de colisión, que alcanza cotas altísimas a medida que aumentan las distancias recorridas y el volumen de tráfico $(18,53,75)$. El uso continuo del automóvil disminuye considerablemente el ejercicio físico y fomenta la obesidad y la mala forma física (83). Por otra parte, el automóvil limita la interacción personal y deteriora las relaciones humanas. Muchos automovilistas de conducta agresiva son personas perfectamente pacíficas cuando no están al volante $(53,75)$.

La transformación urbana impulsada por la difusión del automóvil privado genera un intenso consumo energético (véase el cuadro 3). En las "ciudades de automóviles" se consume cuatro veces más energía por persona que en las ciudades de transporte público y casi 15 veces más que en las ciudades peatonales.

EL AUTOMÓVIL DEVORA LA CIUDAD fue el lema de una campaña de apoyo al transporte público en una ciudad europea. De hecho, los centros urbanos más agradables y atractivos para visitantes y residentes son los de transporte más eficiente desde el punto de vista energético. Como concluyeron Newman y Kenworthy (77) de su extenso estudio de ciudades de varios continentes, el grado en que estas resultan acogedoras y humanas está significativa e inversamente correlacionado con el grado de predominio del automóvil.

\section{El tráfico y el ambiente rural}

En las zonas rurales la construcción de carreteras y autopistas se ha convertido en una de las causas principales de deterioro ambiental, pérdida de terreno cultivable y destrucción de la naturaleza y del paisaje, devorados por anuncios publicitarios, obras de ingeniería y grandes zonas de erosión (84). Algunos de estos efectos pueden prevenirse mediante políticas apropiadas para amortiguar el llamado "impacto ambiental", pero otros son inherentes a la infraestructura del tráfico, que exige enormes cantidades de terreno. Una autopista ocupa aproximadamente seis veces más terreno que un ferrocarril, aunque este tiene una capacidad de transporte de viajeros $67 \%$ mayor (53).

En las zonas "subdesarrolladas", la construcción de carreteras es a menudo la primera fase de un proceso que en pocos años lleva a la desertización. En el noroeste del Brasil las carreteras abrieron el acceso a zonas selváticas en las que se establecieron productores de caucho, café y cacao. Posteriormente, con el colapso de los precios en el mercado mundial, la principal actividad pasó a ser la tala de árboles para su venta como madera, que llevó a la deforestación de toda el área (52).

\section{Los costos de los efectos nocivos del tráfico}

Calcular los costos que suponen la muerte o las lesiones de una persona en productividad perdida y gastos de atención sanitaria y de otro tipo no implica necesariamente adjudicarle un precio a su vida o a su salud. ${ }^{5}$ Según ese tipo de cálculos, en los Estados Unidos cada defunción por LT cuesta cuatro veces más que una defunción por cáncer y siete veces más que una por enfermedad cardiovascular. Ese mayor costo de las muertes debidas al tráfico refleja la edad promedio bastante menor a la que estas suelen producirse. Los traumatismos no mortales y las discapacidades por LT tienen costos enormes por los largos períodos de intenso tratamiento, sobre todo en los casos de parálisis o lesión cerebral (47).

Según distintas estimaciones, el costo total de la morbilidad y la mortalidad generadas por las LT equivaldría a una proporción de 0,5 a 1,5\% (13) o 2\% (52) del producto nacional bruto (PNB). En 1990 los costos totales de morbilidad, mortalidad y daños materiales producidos por colisiones de tráfico ascendieron en los Estados Unidos a 137500 millones de dólares (39), lo

\footnotetext{
5 Lo que sería inmoral o absurdo a juicio de muchos autores, incluido quien suscribe.
} 
que supone 2,4\% del PNB (5,76 billones) de ese año (85). Claro que en la particular contabilidad expresada por el PNB, esos costos debidos a cuentas de hospitales, honorarios médicos, gastos de reparación de infraestructuras y facturas de los talleres de reparación de vehículos y de las funerarias, engrosan la "renta nacional" y se convierten así en índice "macroeconómico" de la riqueza del país.

En el Reino Unido, la Comisión Real para la Protección Ambiental (52) ha estimado que los costos mínimos generados por la contaminación atmosférica, el ruido, la vibración y el cambio climático debidos al tráfico ascenderían a $4,6 \%$ del producto interno bruto.

\section{Automóvil y economía}

El uso habitual del automóvil requiere una extensa infraestructura viaria que suele correr a cuenta de los presupuestos generales del estado (52, 84). Como en la mayor parte del mundo solo una minoría dispone de automóvil, el conjunto de la población financia mediante sus impuestos la infraestructura que utilizan predominantemente unos pocos. Las infraestructuras viarias constituyen así un tipo de obras públicas especialmente regresivo en cuanto a redistribución de las rentas (80). Por otra parte, el auge del transporte por carretera tiene efectos nocivos para el ferrocarril —un medio de transporte mucho menos contaminante y más eficiente desde el punto de vista energético-, que pierde pasajeros, mercancías y apoyo financiero hasta llegar al cierre de líneas férreas por falta de rentabilidad, como ha ocurrido en años recientes en países como Argentina, España, Estados Unidos y Francia (52).

$\mathrm{Si}$ todos tenemos derecho al espacio urbano y al aire respirable, quienes no usan automóviles, además de no contaminar favorecen a los automovilistas al no ocupar la parte de la vía pública "que les correspondería" si usaran automóvil. La deducción inmediata (86) es que, para defender el bien público, que es un espacio urbano sano y tranquilo, hay que gravar con impuestos fuertes a los automovilistas $\mathrm{y}$ favorecer fiscalmente a quienes usan otro tipo de transporte. Según cálculos de la Federación Europea para el Transporte y el Ambiente (52), los precios actuales de la gasolina en Europa solo cubren de 40 a $70 \%$ del total de gastos por externalidades (o sea, los efectos nocivos) generadas por el tráfico. Es de notar que los precios europeos equivalen aproximadamente a vez y media los de Perú y Bolivia, tres veces los de Estados Unidos, cuatro veces los de China, siete veces los de Rusia y unas 60 veces mayores los de Venezuela.

\section{Un fetiche moderno nocivo para la salud}

Tal como señaló la economista Joan Robinson (87), “el automóvil privado es un caso paradigmático de un tipo de consumo que causa disutilidad: cuanta más gente lo usa, más desagradable se hace la vida, hecho dolorosamente obvio que la doctrina [económica] ortodoxa ha sido incapaz de integrar".

Las sumas astronómicas que gasta en publicidad la industria del automóvil han logrado difundir la imagen de un objeto deseable que ha de poseer toda persona "que se precie". El "aura" en torno al automóvil es tal que como ha dicho un epistemólogo, "San Auto y Santa Tele tienen hoy más devotos que San Antonio o Santa Cecilia" (88). En esto como en otras cosas, la publicidad tiene efectos claramente nocivos para la salud pública (89). Las falsas imágenes y expectativas que alimenta la publicidad a menudo favorecen la conducción peligrosa (al ocultar sistemáticamente los riesgos del automóvil para sus ocupantes y para los demás), enmascaran los perjuicios derivados del tráfico (al presentar vehículos que "vuelan" por paisajes naturales de ensueño, frente a la realidad diaria de los atascos urbanos) y fomentan una ideología individualista que excluye la solución colectiva de los problemas de transporte (16). En realidad, el automóvil es una máquina que facilita el desplazamiento a costa de importantes perjuicios individuales y colectivos (84). Afortunadamente para la humanidad, la mayor parte de los seres humanos no tienen automóvil.

\section{Reducir el volumen de tráfico: una política urgente de promoción de la salud}

La promoción de la salud se ha definido como un proceso que permite a los individuos y a las comunidades mejorar y mantener su bienestar físico, mental y espiritual. Una parte fundamental de esa promoción es la aplicación de políticas generales saludables (90), las cuales a menudo implican a muy diversos sectores sociales. La política de transporte es hoy tan importante para la salud nuestra y la de generaciones futuras como la de agricultura o de educación.

En gran parte del mundo el automóvil privado solo está al alcance de una minoría, pero al actual ritmo de producción anual de decenas de millones de vehículos, la motorización del planeta parece inevitable. Sin embargo, desplazar al automóvil privado como medio habitual de transporte en los países industrializados y evitar su generalización donde todavía es infrecuente es claramente deseable, no solo para reducir una causa fundamental de muerte, lesión, enfermedad y discapacidad, sino también como eje a partir del cual el desarrollo social pueda encaminarse por vías sostenibles.

Históricamente, muchas medidas favorables a la salud pública han encontrado gran oposición y han sido muy difíciles de llevar a la práctica. Una política que promueva el transporte público y desincentive el automóvil privado suscitará enormes resistencias. Los beneficios son muy difusos (para la sociedad en general e incluso para generaciones futuras) mientras que los inconvenientes se concentran, además en grupos poderosos (los fabricantes de automóviles en primer término y en segundo lugar los automovilistas, que constituyen una gran proporción en los países ricos y las minorías poderosas en los pobres). 
En estos casos es difícil que se tomen medidas legislativas eficaces (91).

Avanzar hacia una sociedad en la que el automóvil se relegue a usos específicos probablemente exigirá muchas tentativas. En bastantes ciudades se ha hecho evidente la necesidad de restringir el tráfico, desincentivar o prohibir el uso del automóvil privado, promover el transporte público y crear zonas exclusivas para peatones (82). Las experiencias son muy diversas y muchas de ellas han resultado insuficientes. En la ciudad de México funciona desde hace años el programa HOY NO CIRCULA, que cada día de la semana prohíbe circular a los automóviles con determinados números de placa. El programa hubo de intensificarse en febrero de 1996, ante un gran aumento de la contaminación. ${ }^{6}$ Por razones similares, en febrero de 1992 se prohibió la circulación de gran parte del parque automovilístico de Santiago, Chile (40). En los Estados Unidos, en las carreteras denominadas HOV solo se permite circular a vehículos ocupados al menos por tres personas y en muchas ciudades europeas se han creado zonas centrales peatonales, prohibidas para los automóviles privados. En Austria, Suiza y Hungría, se han tomado medidas para prevenir la contaminación y ahorrar energía encauzando hacia el ferrocarril el tráfico de carretera. En varias ciudades escandinavas se han implantado peajes para los automóviles que cruzan hacia el interior de la ciudad (52). En los años ochenta en muchas ciudades nórdicas y holandesas se tomaron

G. A. Silva, OPS, comunicación personal. medidas para asegurar un tráfico lento y dar prioridad a los peatones y ciclistas. El resultado ha sido la tasa de LT más baja de Europa (58). Desde los años ochenta Dinamarca adoptó políticas para desincentivar la propiedad de automóvil (92) y recientemente el transporte público se ha hecho gratuito en varias ciudades nórdicas. En Singapur está en marcha un plan gubernamental para restringir drásticamente las matriculaciones de vehículos, convertir todas las carreteras en vías de peaje en 1997 y simultáneamente mejorar el sistema de transporte público, ya integrado por una extensa red de modernos ferrocarriles suburbanos y autobuses (75).

En la ciudad brasileña de Curitiba la planificación urbana ha favorecido el transporte público a base de autobuses desde los años sesenta. Con más de dos millones de habitantes, Curitiba hoy tiene tasas de contaminación y de criminalidad menores que las de ciudades similares y mayores niveles educativos y proporción de zonas verdes urbanas. Las políticas urbanísticas de Curitiba se han considerado un modelo de gestión pública (93), aunque la tasa de mortalidad por LT en esa ciudad no parece apoyar la idea (30).

Las políticas que fomentan medios de transporte más sanos y menos contaminantes que el automóvil privado benefician la salud pública y liberan recursos para otras actividades. Las zonas urbanas peatonales, las limitaciones de velocidad y la colocación en calles y carreteras de obstáculos que obligan a reducir la velocidad mejoran la calidad de vida en las ciudades y permiten salvar vidas y evitar discapacidades. La limitación de la velocidad - que reduce además el consumo de combustible y la contaminación-,las medidas legislativas y fiscales para reducir el consumo de alcohol, las sanciones graves a quienes conducen tras consumir alcohol y, en general, a quienes no respetan las normas de circulación, pueden contribuir a esos mismos objetivos $(9,10,14)$. Asimismo la integración de las zonas de trabajo, vivienda y actividades recreativas en ciudades de media o alta densidad es una política favorable a la salud pública porque disminuye el volumen de tráfico y los riesgos y la contaminación asociados (94).

Cada día es más general el consenso científico respecto a las consecuencias nocivas para la humanidad de un modelo económico basado en un consumo energético que aumenta exponencialmente (95). Por otra parte, la experiencia del siglo XX muestra claramente que la carga de enfermedad y muerte generada por los automóviles guarda relación directa con el volumen de tráfico. Disminuir ese volumen es una política urgente y necesaria de promoción de la salud, quizá una de las más importantes para la humanidad, a mediano y largo plazo. ${ }^{7}$

\section{Agradecimiento}

Agradezco a Benigno Asensio, Joan Benach y Ana Diez Roux su colaboración directa e indirecta a la versión final de este texto.

\footnotetext{
Este artículo estaba ya listo para imprenta, cuando en diciembre de 1997 se celebró en Kioto, Japón, la Conferencia Mundial sobre el Cambio Climático, un signo más, a mi juicio, de la importancia de algunos temas aquí tratados (N. del autor).
}

\section{REFERENCIAS}

1. Motor Vehicle Manufacturers Association of the United States. World motor vehicle data, 1977 edition. Washington, DC: MVMA; 1977:12.

2. Auto \& Truck International. World automotive market report 1996-1997. 66a ed. Arlington Heights, IL: Adams Trade Press; 1996: 24-25.
3. Wolf $\mathrm{W}$. La sociedad del automóvil: un callejón sin salida. Mientras Tanto (Barc) 1995; 61:97-108.

4. United Nations. World statistics pocketbook. New York: 1995.

5. Durning AT. How much is enough: the consumer society and the future of the Earth. New York: W. W. Norton; 1992:25
6. Rothman K, ed. Causal inference. Chestnut Hill, MA: Epidemiology Resources; 1988.

7. Hill AB. Ambiente y enfermedad: ¿asociación o causación? Bol Oficina Sanit Panam 1992;113: 233-242 [ed. orig.: The environment and disease: association or causation? Proc $R$ Soc Med 1965;58:295-300]. 
8. Eells E. Probabilistic causality. Cambridge: Cambridge University Press; 1991.

9. Robertson LS. Injuries: causes, strategies and public policy. Lexington, MA: Lexington Books; 1983: 117-134, 140-144, 185-208.

10. Robertson LS. Injury epidemiology. New York: Oxford University Press; 1992:138-142, 147-170.

11. Robertson LS. Reducing death on the road: the effects of minimum safety standards, publicized crash tests, seat belts, and alcohol. Am I Public Health 1996;86:31-34.

12. Williams AF, Carsten O. Driver age and crash involvement. Am J Public Health 1989;79: 326-327.

13. Robertson LS, Maloney A. Motor vehicles rollover and static stability: an exposure study. Am J Public Health 1997;87:839-841.

14. Waller AE, Baker SP, Szocka A. Childhood injury deaths: national analysis and geographic variations. Am J Public Health 1989; 79:310-315.

15. Perneger T, Smith GS. The driver's role in fatal two-car crashes: a paired "case-control" study. Am J Epidemiol 1991;134:1138-1145.

16. Davis R. Death on the streets: cars and the mythology of road safety. Burtersett, Hawes, North Yorkshire: Leading Edge Press; 1993: 38.

17. Hingson R, Heeren T, Winter M. Lowering state legal blood alcohol limits to $0.08 \%$ : the effect on fatal motor vehicle crashes. Am I Public Health 1996;86:1297-1299.

18. Durning AT. The car and the city. Seattle, WA: Northwest Environment Watch; 1996.

19. Jernigan JD, Strong SE, Lynn CW. Impact of the 65 mph speed limit on Virginias' rural interstate highways: 1989-1992. Charlottesville, VA: Virginia Transportation Research Council; 1994 (VTRC 95-R7)

20. Plasència i Taradach A, Ferrando i Belart J. Epidemiología de los accidentes de tráfico. En: Álvarez González FJ, coord. Seguridad vial y medicina de tráfico. Barcelona: Masson, 1997:1-23.

21. Evans L. The dominant role of driver behaviour in traffic safety. Am J Public Health 1996; 86:784-786.

22. Waller JA. Injury as disease. Accid Anal Prev 1987;19:13-20.

23. Langley JD. The need to discontinue the use of the term "accident" when referring to unintentional injury events. Accid Anal Prev 1988;20:1-8.

24. Loimer H, Guarneri M. Accidents and acts of God: a history of the terms. Am J Public Health 1996;86:101-107.

25. Waller JA. Injury as a public health problem. En: Last JM, ed. Public health and preventive medicine. 11a ed. New York: AppletonCentury-Crofts: 1980:1549-1563.

26. Waller JA. Injury control: a guide to the causes and prevention of trauma. Lexington, MA: Lexington Books; 1985:107-224.

27. Glizer IM. Prevención de accidentes y lesiones. Washington, DC: Organización Panamericana de la Salud; 1993:2, 24-27.

28. World Health Organization. International statistical classification of diseases and related health problems. Vol 1, 10a rev. Geneva: WHO; 1992. [Versión en castellano: Clasificación estadística internacional de enfermedades y problemas relacionados con la salud. Vol 1, 10a rev. Washington, DC: Organización Panamericana de la Salud; 1995. (Publicación científica 353)].
29. Graitcer PL. Injury surveillance in developing countries. MMWR 1992:41:SS-1:15-20.

30. Mello Jorge MHP, Latorre MRDO. Accidentes de tránsito no Brasil: dados e tendências. Cad Saude Publica (Rio de Janeiro) 1994:10(supl. 1):19-44.

31. Ott EA, Favaretto ALF, Neto AFPR, Zechin JG, Bordin R. Accidentes de trânsito em área metropolitana da região sul do Brasil: caracterização da vítima e das lesões. Rev Saude Publica 1993;27:350-356.

32. Murray CJL, Lopez AD. Patrones de distribución mundial y regional de las causas de defunción en 1990. Bol Oficina Sanit Panam 1995;118:307-345 [orig. en inglés]: Global and regional cause-of-death patterns in 1990. Bull World Health Organ 1994;72:447.

33. WHO. The world health report 1995: bridging the gaps. Geneva: World Health Organization; 1995:2, 19

34. Söderlund N, Zwi AB. Traffic-related mortality in industrialized and less developed countries. Bull World Health Organ 1995;73:175-182 [trad. en español: Mortalidad por accidentes de tráfico en países industrializados y en desarrollo. Bol Oficina Sanit Panam 1995;119: 471-480].

35. Stansfield SK, Gordon SS, McGreevey WP. Injury. En: Jamison DT, Mosley WH, Measham AR, Bobadilla JL, eds. Disease control priorities in developing countries. New York; Oxford University Press; 1993:609-633.

36. Waller JA. Injury control in perspective. Am J Public Health 1989;79:272-273.

37. Nordheimer J. Gender gap not worth closing Women show that they can drive as bad as men. New York Times. 10 August 1996:19, 21.

38. WHO. World Health Statistics Annual 1994. Geneva: World Health Organization; 1995.

39. US Department of Transportation, Office of Plans and Policy, National Highway Traffic Safety Administration. Saving lives and dollars: highway safety contribution to health care reform and deficit reduction. Washington, DC: USGPO 1993.

40. OPS. Las condiciones de salud en las Américas: edición de 1994. Washington, DC: Organización Panamericana de la Salud; 1994 (CD-ROM).

41. Lopez AD, Caselli G, Valkonen T. Moving from description to explanation of adult mortality: issues and approaches. En: Lopez AD, Caselli G, Valkonen T, eds. Adult mortality in developed countries: from description to explanation. Oxford: Clarendon Press; 1995.

42. Eyer J. Prosperity as a cause of death. Int J Health Services 1977:7:125-151.

43. Eyer J. Does unemployment cause the death rate peak in each business cycle? A multifactorial model of death rate change. Int $J$ Health Services 1977b;7:625-662.

44. Highway Loss Data Institute insurance special report: relationship between losses and vehicle density. Washington, DC: HLDI; 1985.

45. Roberts I, Crombie I. Child pedestrian deaths: sensitivity to traffic volume evidence from the USA. J Epidemiol Comm Health 1995;48:186-188 [resumen en español: Defunciones infantiles por atropello. Bol Oficina Sanit Panam 1996; 120:61].

46. Havemann R. La libertad como necesidad: escritos berlineses [versión castellana: R. Reig]. Barcelona: Laia; 1979:71-73.

47. Krauss JF, Robertson LS. Injuries and the public health. En: Last JM, Wallace RB, eds. Public health and preventive medicine. 13a ed. Norwalk, CN: Appleton \& Lange; 1992:1129-1131.

48. Yunes J, Rajs D. Tendencia de la mortalidad por causas violentas en la población general y entre los adolescentes y jóvenes de la Región de las Américas. Cad Saude Publica (São Paulo) 1994;10(supl 1):88-125.

49. Evans AW. Evaluating public transport and road safety measures. Accid Anal Prev 1994; 26:411-428

50. OMS. Nuestro planeta, nuestra salud: Informe de la Comisión de Salud y Medio Ambiente de la OMS. Washington, DC: Organización Panamericana de la Salud: 1993:158-168. (Publicación científica 544).

51. Costa Rica, Ministerio de Salud. Informe anual 1995. San José: Ministerio de Salud; 1996: $15-16$.

52. World Bank. Sustainable transport: priorities for policy reform. Washington, DC; The World Bank: 1996:52, 57, et passim.

53. Freund P, Martin G. The ecology of the automobile. Montreal/New York: Black Rose Books; 1993:16-19, 23, 47, 49, 112.

54. Wald ML. Cutoff switches for car airbags will be allowed. New York Times 1997, Nov 18:A1, A20.

55. Wald ML. More children are killed by air bags, and parents are blamed. New York Times 1996; September 18, A16

56. Flavin C. Facing up to the risks of climate change. En: Brown LR, Abramovitz J, eds. State of the world 1996. New York: Norton; 1996: 21-39.

57. Roberts I. What does a decline in child pedestrian injury rates mean? [carta]. Am J Public Health 1995;85:268.

58. Hunt SM. The public health implications of private cars. En: Martin CJ, McQueen DV, eds. Readings for a new public health. Edinburgh: Edinburgh University Press: 1989:100-115.

59. Romieu I, Weitzenfeld H, Finkelman J. Urban air pollution in Latin America and the Caribbean: health perspectives. World Health Stat Q 1990;43:153-167.

60. Weitzenfeld $\mathrm{H}$. Contaminación atmosférica y salud en América Latina. Bol Oficina Sanit Panam 1992;112:97-109 [versión en inglés en Bull Pan Am Health Organ 1992;26:18-29].

61. Sunyer J, Antó JM, Murillo C, Saez M. Effect of urban air pollution on emergency room admissions for chronic obstructive pulmonary disease. Am J Epidemiol 1991;134: 277-286.

62. Ballester Díez F, Merino Egea C, Pérez Hoyos $\mathrm{S}$. La asociación entre contaminación atmosférica y mortalidad: una revisión de los estudios epidemiológicos recientes. Rev Esp Salud Publica 1995:69:177-187.

63. Medina S, Dab W, Quenel P, Ferry R, Festy B. Urban air pollution is still a public health problem in Paris. World Health Forum 1996;17: 187-193.

64. Dockery DW, Pope III CA, Xu X, Spengler JB, Ware $\mathrm{JH}$, Fay ME, et al. An association between air pollution and mortality in six US cities. N Engl J Med 1993; 32:1753-1759.

65. Salinas M, Vega J. The effect of outdoor air pollution on mortality risk: an ecological study from Santiago, Chile. World Health Stat Q 1995;48:118-125.

66. Stephens C, Akerman M, Maia PB. Health and environment in São Paulo, Brazil: methods of data linkage and questions of policy. World Health Stat Q 1995; 48:95-107. 
67. López Bravo IM, Sepúlveda H, Valdés I. Enfermedades respiratorias agudas en los primeros 18 meses de vida. Bol Oficina Sanit Panam 1996; 120:278-388.

68. Centers for Disease Control and Prevention. Asthma mortality and hospitalization among children and young adults, United States, 1980-1993. MMWR 1996;45:350-353.

69. Wolf SP. Re: "Invited commentary: how much retropsychology" [carta]. Am J Epidemiol 1991: 135:1314-1315.

70. Murray CJL, Lopez AD, Jamison DT. La carga global de enfermedad en 1990: resumen de los resultados, análisis de la sensibilidad y orientaciones futuras. Bol Oficina Sanit Panam 1995;118:510-528 [original en inglés: The global burden of disease in 1990: summary results, sensitivity analysis and future directions. Bull World Health Organ 1994;72: 495-510).

71. Murray CJL, Lopez AD. The global burden of disease in 1990: final results and their sensitivity to alternative epidemiological perspectives, discount rates, age weights and disability weights. En: Murray CJL, Lopez AD, eds. The global burden of disease: a comprehensive assessment of mortality and disability for diseases, injuries, and risk factors in 1990 and projected to 2020. Cambridge: Harvard University Press/ World Health Organization/World Bank; 1996:247-294.

72. Houghton JT, Meira Filho LG, Callander BA, Harris N, Kattenberg A, Maskell K, eds. Climate change 1995: the science of climate change Contribution of Working Group I to the Second Assesment Report of the Intergovernmental Panel on Climate Change. Cambridge: Cambridge University Press; 1996.

73. Patz JA, Epstein PR, Burke TA, Balbus JM. Global climate change and emerging infectious diseases. JAMA 1996;275:217-223.

74. Watson RT, Zinyowera MC, Moss RH, eds. Climate change 1995: impacts, adaptations and mitigation of climate change: scientific-technical
analyses-Contribution of Working Group II to the Second Assessment Report of the Intergovernmental Panel on Climate Change. Cambridge: Cambridge University Press; 1996 (Summary for policy-makers).

75. Bushell C. Foreward. En: Jane's urban transport systems 1996-1997. 15a ed. Coulsdon, Surrey: Jane's Information Group LTD; 1996.

76. Lawton J. What will you give up? Oikos 1994;71:353-354.

77. Newman P, Kenworthy J. Cities and automobile dependence: an international sourcebook. Aldershot: Gower Technical; 1989:3, 83.

78. Jackson KT. Craborass frontier: the suburbanization of the United States. New York: Oxford University Press; 1985;12-20, 272-282.

79. Jackson KT. America's rush to suburbia. New York Times 1996, June 9, E15.

80. Harvey D. Social justice and the city. Baltimore, MD: The Johns Hopkins University Press; 1973.

81. US Bureau of Census. Statistical abstract of the United States 1995. 115a ed. Washington, DC: 1995:234.

82. World Health Organization; The urban health crisis: strategies for health for all in the face of rapid urbanization. Geneva: WHO; 1993.

83. World Health Organization/Fédération internationale de Médecine sportive, Committee on Physical Activity for Health. Exercise for health. Bull World Health Organ 1995;73: 135-136.

84. Robinson J. Highways and our environment. New York: McGraw-Hill; 1971.

85. Economic Report to the President 1997. Washington, DC: Government Printing Office; 1997.

86. Warford JJ. Environment, health and sustainable development: the role of economic instruments and policies. Bull World Health Organ 1995;73:387-396.

87. Robinson J. What are the questions. En: "What are the questions?" and other essays: further con- tributions to modern economics. Armonk, NY: Sharpe; 1980:1-33.

88. Bunge M. Sistemas sociales y filosofía. Buenos Aires: Sudamericana; 1995.

89. Wallack L, Montgomery K. Advertising for all by the year 2000: public health implications for less developed countries. J Public Health Pol 1992:13;204-223. Reimpreso en: Pan American Health Organization. Health promotion: an anthology. Washington, DC: $\mathrm{PAHO}$ 1996:256-267. (Scientific publication 557).

90. McKinlay JB. Health promotion through healthy public policy: the contribution of complementary research methods. Can J Public Health 1992;sup.1 (March-April):811-819. Reimpreso en: Pan American Health Organization. Health promotion: an anthology. Washington, DC: PAHO; 1996:54-67. (Scientific publication 557).

91. Christoffel T, Christoffel KK. The Consumer Product Safety Commission's opposition to consumer product safety: lessons for public health advocates. Am J Public Health 1989; 79: 336-339.

92. Brown LR. Reconsidering the automobile's future. En: Brown LR, et al. State of the world 1984. New York: Norton; 1984: 157-164.

93. Rabinovitch J, Leitman J. Urban planning in Curitiba. Sci Am 1996;274:46-53.

94. Ashton J. Sanitarian becomes ecologist: the new environmental health. Br Med J 1991;301: 189-190.

95. Georgescu-Roegen N. Energy and economic myths. En: Energy and economic myths: institutional and analytical economic assays. New York: Pergamon; 1976:3-36.

Manuscrito recibido el 5 de septiembre de 1996 y aceptado para publicación en versión revisada el 19 de septiembre de 1997.
ABSTRACT

\section{A reduction in automobile traffic: an urgent health promotion policy}

During the last few decades, traffic injuries have become one of the leading causes of death and disability in the world. In urban areas, traffic congestion, noise, and emissions from motor vehicles produce subjective disturbances and detectable pathological effects. More than one billion people are exposed to harmful levels of environmental pollution.

Because its combustion engine generates carbon dioxide $\left(\mathrm{CO}_{2}\right)$, the automobile is one of the chief sources of the gases that are causing the greenhouse effect. The latter has already caused a rise in the average ambient temperature, and over the next decades it will predictably cause significant climatic changes whose consequences, though uncertain, are likely to be harmful and possibly catastrophic. Aside from the greenhouse effect, the relentless growth of parking zones, traffic, and the roadway infrastructure in urban and rural areas is currently one of the leading causes of environmental degradation. Urban development, which is nearly always "planned" around traffic instead of people, leads to a significant deterioration in the quality of life, while it also destroys the social fabric.

Unlike the private automobile, public transportation, bicycles, and walking help reduce pollution, congestion, and traffic volume, as well as the morbidity and mortality resulting from injuries and ailments related to pollution. Non-automobile transportation also encourages physical activity-with its positive effect on general health-and helps reduce the greenhouse effect. The drop in traffic volume and the increased use of alternate means of transportation are thus an integrated health promotion policy which should become an inherent part of the movement for the promotion of healthy cities and of transportation policies and economic policy in general. 